\title{
Effect of mobility score on milk yield and activity in dairy cattle
}

\author{
J. D. Reader, ${ }^{*}$ M. J. Green,† J. Kaler,† S. A. Mason, $\ddagger$ and L. E. Green ${ }^{1}$ \\ *Synergy Farm Health, West Hill Barns, Evershot, Dorset, DT2 OLD, United Kingdom \\ †The School of Veterinary Medicine and Science, University of Nottingham, Sutton Bonington Campus, Sutton Bonington, Leicestershire, \\ LE12 5RD, United Kingdom \\ $\ddagger$ School of Life Sciences, University of Warwick, Coventry, CV4 7AL, United Kingdom
}

\begin{abstract}
Previous studies have indicated that lame cows have reduced milk yield both before and after they are treated for lameness. One explanation for the reduction in yield before treatment is delay to treatment; that is, cows have impaired mobility for some time before they are treated. The aim of this study was to test this hypothesis by investigating temporal associations between change in milk yield and change in mobility score. Mobility score (MS, on a scale from 0 to 3), milk yield, treatments for lameness, and cow activity were recorded on 312 cows in a dairy herd in Somerset, UK, for $1 \mathrm{yr}$. The MS was scored every 2 wk and compared with daily yield and activity (mean log steps/h) averaged over the previous $16 \mathrm{~d}$. Approximately $52 \%$ of MS changed within $14 \mathrm{~d}$, usually by 1 unit. Overall, milk yields of cows with MS 1 were greater than those of cows with other scores. Cows with MS 2 and 3 produced 0.7 (95\% confidence interval: 0.35-0.97) and 1.6 (0.98-2.23) kg less milk/d, respectively, compared with cows with MS 1 . In addition, cows with MS 1 were significantly more active than cows with MS 0, 2, or 3 . Cows with MS 2 and 3 were $0.02(0.01-0.03)$ and 0.03 (0.01-0.05) mean log steps less active than cows with MS 1. Six to 8 wk before nonlame cows became MS 2 or 3 , their daily milk yield decreased by a mean (95\% CI) of $0.5 \mathrm{~kg}(0.12-0.47)$ and $0.9 \mathrm{~kg}(0.16-1.65)$ respectively. Daily yield remained lower by $0.42 \mathrm{~kg}(0.09-0.75)$ for 4 wk after cows with MS 2 had recovered. The activity of cows was significantly less (0.01 mean log steps) with increasing MS; the associations between activity and parity (means 0.03-0.11) and month of lactation (means 0.03-0.36) were quantitatively larger. Results from a multistate model indicated that once cows were lame they remained lame or became lame again despite treatment. In conclusion, cows' milk production started to decline before their mobility was visibly impaired.
\end{abstract}

Received April 4, 2011.

Accepted June 17, 2011.

${ }^{1}$ Corresponding author: laura.green@warwick.ac.uk
Key words: cow, milk yield, lameness, multistate model

\section{INTRODUCTION}

The prevalence and incidence of lameness in dairy cows in intensive systems is high, with estimates of prevalence in the UK ranging from 21\% (Clarkson et al., 1996) to $36 \%$ (Leach et al., 2010). Lame cows are in pain and their welfare is compromised (Whay et al., 1997).

Lameness is associated with a reduction in milk yield (Juarez et al., 2003; Archer et al., 2010). This reduced milk yield is present before and after a treatment event, but varies with the type of lesion (Green et al., 2002; Amory et al., 2008; Bicalho et al., 2008). The reduction in yield detected before a treatment event with noninfectious horn lesions (Amory et al., 2008; Green et al., 2010) might occur because of a long pathogenesis in disease before cows become lame or because of delayed treatment. It is less evident that infectious claw conditions are associated with reduced milk yield before cows are observed to be lame (although Warnick et al., 2001 reported that interdigital phlegmon was associated with reduced yield before treatment in one herd), possibly because the progression from infection to lameness is rapid. For both types of disorders, delay in treatment would probably lead to reduced milk yield because of the increased metabolic demands from pain and reduced feed intake. The treatment of lame cows depends on the ability of farmers to recognize a lame cow and to treat affected cows promptly and appropriately. Most dairy farmers underestimate the prevalence of lameness on their farms (Whay et al., 2003) and do so inconsistently compared with a trained researcher (Leach et al., 2010), suggesting that most dairy cow herdsmen do not have a logical way of detecting lameness.

Mobility scoring has been developed to help farmers improve detection of mild lameness and stimulate treatment and prevention as part of a herd health program. The accepted system used in the UK is a 4-point mobility scoring (mobility score, $\mathbf{M S}$, on a scale from 0 
to 3) system (Whay et al., 2003). This system is used by many researchers and veterinary practitioners, but has not been evaluated for repeatability. Some authors have reported that daily activity levels are lower in cows with reduced mobility (O'Callaghan et al., 2003; Mazrier et al., 2006; Walker et al., 2008).

The current study was designed to test the hypothesis that the reduction in milk yield that occurs before lame cows are treated is due to delayed treatment. This was tested by investigating the temporal association between change in milk yield and change in locomotion and time to treatment. The MS, milk yield, and activity in cattle from a single farm were observed every 2 wk for $1 \mathrm{yr}$ to estimate precise relationships between MS and changes in MS, milk yield, and cow activity.

\section{MATERIALS AND METHODS}

\section{Experimental Design}

A dairy herd that calved all year round, located in Somerset, UK, with a milking herd of 200 Holstein cows, producing approximately 9,000 kg of milk/cow per year was used for the study. The study started on October 24, 2007, and finished on November 5, 2008. The number of cows in milk ranged from 168 (November 5, 2008) to 217 (April 23, 2008), with a mean of 197 and median of 200. The herd was divided into 2 groups of about equal size based on milk yield, both housed in 1 building with a floor of concrete and 230 freestalls fitted with mattresses and bedded with sawdust. Milking cows had access to pasture in summer, with high-yielding cows on pasture for only a limited period each day. Nonlactating cows were kept in a separate building and their locomotion was not scored. The herd was milked twice daily through an 18/36 herringbone parlor. Milking cows walked through a $5 \%$ formalin footbath once each week as they exited the parlor.

Cows were selected for foot trimming by the herdsman. Approximately 35 cows were trimmed per month; foot trimming was carried out by a paraprofessional foot trimmer from Kingfisher Veterinary Practice (Synergy Farm Health, West Hill Barns, Evershot, Dorset, UK).
The selection criteria for foot trimming were cows that were clinically lame (MS 2 or 3 ) or cows that were due to be dried off. The farmer intended to trim the feet of each cow at least once each year, but this was not verified. Lesions were defined using the definitions in the EU Lamecow Project (Barker et al., 2007), and all foot trimming and lameness were recorded on lameness scoring sheets designed by the EU Lamecow project. Both herdsman and veterinarian recorded lameness treatments in the same way.

All cows were individually identified and fitted with pedometers (Westfalia Dairy Plan C21 (GEA Farm Technologies Australia Pty. Ltd., Tullamarine, Victoria, Australia). Activity readings for each cow were automatically downloaded to the farm computer in the parlor twice daily and onto a laptop computer once weekly. The mobility of lactating cows was scored (Table 1) every 2 wk after evening milking by the first author using the system described by Whay et al. (2003). The identity of each cow was recorded as she entered the parlor, and mobility was scored and recorded on standardized sheets as the cow exited the parlor. The MS was transferred to an Excel 2003 spreadsheet (Microsoft Corp., Redmond, WA). Milk yield, activity (steps/h), health records, lameness records, and group were downloaded from the farm computer into the spreadsheet.

\section{Data Analysis}

The mean proportion of cows with each MS by stage of lactation ( 1 to $90 \mathrm{~d}, 91$ to $180 \mathrm{~d},>180 \mathrm{~d}$ ), mean milk yield, and mean activity over the previous $16 \mathrm{~d}$ were calculated. The probability of transition between MS from time $t$ to time $t+1,14 \mathrm{~d}$ later, was estimated. Two multilevel statistical models were constructed using conventional methods (Goldstein, 1995). In the first model, the outcome variable was mean milk yield in the $16 \mathrm{~d}$ before a MS, and the effect of MS before and after this outcome was investigated. In the second model, mean $\log _{10}$ steps (activity score) for the previous $16 \mathrm{~d}$ was the outcome and the effect of MS on activity was investigated.

The models took the form

Table 1. Definitions of mobility scores (Whay et al., 2003)

\begin{tabular}{lll}
\hline $\begin{array}{l}\text { Mobility } \\
\text { score }\end{array}$ & Definition & Description of cow mobility \\
\hline 0 & Good mobility/sound & $\begin{array}{l}\text { Walks with even weight-bearing and rhythm on all } 4 \text { feet } \\
\text { with a flat back. Long fluid strides possible. }\end{array}$ \\
1 & Imperfect mobility & $\begin{array}{l}\text { Steps unevenly or shortened strides. Affected } \\
\text { limbs not immediately identifiable. }\end{array}$ \\
2 & Uneven weight-bearing on limb immediately identifiable or \\
3 & obviously shortened stride. Usually arched back. \\
& Severely impaired mobility & Unable to walk as fast as brisk human pace plus signs of score 2. \\
\hline
\end{tabular}




$$
\begin{gathered}
Y_{i j}=\alpha+\beta_{1} \mathbf{X}_{i j}+\beta_{2} \mathbf{X}_{j}+v_{j}+e_{i j}, \\
v_{j} \sim N\left(0, a_{v}^{2}\right) \\
e_{i j} \sim N\left(0, a_{e}^{2}\right)
\end{gathered}
$$

where the subscripts $i$ and $j$ denote the $i$ th observation of the jth cow, respectively; $\alpha$ is the regression intercept; $\mathbf{X}_{i j}$ is the vector of covariates associated with each observation; $\beta_{1}$ the coefficients for covariates $\mathbf{X}_{i j}$; $\mathbf{X}_{j}$ the vector of covariates associated with each cow; $\beta_{2}$ the coefficients for covariates $\mathbf{X}_{j}$; $v_{j}$ a random effect to reflect residual variation between cows, which is normally distributed with mean $=0$ and variance $=$ $\sigma^{2}$; and $e_{i j}$ a random effect to reflect residual variation between MS, which is normally distributed with mean $=0$ and variance $=\sigma^{2}$. The analysis was carried out using MLwiN 2.02 with penalized quasi-likelihood for parameter estimation (Rasbash et al., 2005). Covariates were left in the model when the significance probability was $P<0.05$ based on the Wald test. When mean milk yield was the outcome, DIM, the exponential DIM ${ }^{-0.05}$ (Wilmink, 1987), and parity 1, 2, 3, and >3, and first or second lactation in the study were forced into the model. Then, the discrete variable $\operatorname{MS}(0,1,2$, and 3$)$ at time $t$ was added. The effect of MS at time $t-1$, $t-2, \ldots, t-5$, and $t+1, t+2, \ldots, t+5$, where each time interval $t$ was $14 \mathrm{~d}$, was tested in the model. When $\log$ mean activity was the outcome, parity 1,2 , 3 , and $>3$, second lactation in the study, and month in milk were forced into the model and then the mobility score at times $t, t-1, \ldots, t-5$ and $t+1, \ldots, t+5$, where each time interval $t$ was $14 \mathrm{~d}$, were tested in the model. Missing observations were random and so were fitted in the model as discrete variables to minimize loss of data. The model fit was checked.

Finally, a multistate model was set up to test the factors associated with cows becoming lame, remaining lame, becoming sound, and remaining sound. Mobility score was categorized into 2 states: not lame (scores 0 and 1 ) and lame (scores $>1$ ). A cow was in 1 of 2 states, not lame or lame. An episode was defined as the continuous period of time a cow spent in either state until a transition to the other state occurred. For each episode $j$ for cow $k$, there was an original state $i$ [0 (not lame), 1 (lame)], the duration spent in that state was categorized into discrete time intervals of 14 $\mathrm{d}\left(t_{i}\right.$, measured as $t=1,2 \ldots n$, with $n$ being the maximum duration of an episode), and an outcome event at the end of the discrete time interval, $y$, where $0=$ no change in state, and $1=$ occurrence of a change in state. A logit link function was used to express the ratio of probability of a change in state to probability of no change in the state and took the form

$$
\operatorname{logit}\left[\pi_{i k(t)}\right]=\beta 0_{i}+\alpha_{i}(t)+\beta x_{i k(t)}+u_{k}^{(i)},
$$

where $\pi_{i k(t)}$ is the probability of the state of the cow (lame or not lame), $\beta 0_{i}$ is a state-specific intercept, $\alpha_{i}$ $(t)$ a set of dummy variables for the discrete time interval $t$ depicting duration of state, $\beta x_{i k(t)}$ covariates include a vector of explanatory variables varying by time or cow with a dummy variable for original state, and $u_{k}$ is the between-cow residual variance. The model was run in MlwiN 2.02 (Rasbash et al., 2005) using Markov chain Monte Carlo estimation. The first 5,000 iterations were discarded and then 500,000 iterations were conducted until the chains were visually stable.

\section{RESULTS}

Mobility was scored on 28 occasions; 312 cows (allowing for additions and removals) were scored, with 168 to 217 at each observation, and the number of scores ranged from 5 to 28 per cow. The percentage of scores $0,1,2$, and 3 were $23,45,27$, and 5 , respectively, with $1,20,48$, and $31 \%$ of cows with maximum scores of 0 , 1,2 , and 3, respectively. The mean number of observations with MS 2 or 3 was $32 \%$, ranging from $24 \%$ in October 2008 to $40 \%$ in July 2008. The mean ( \pm $\mathrm{SE}$ ) duration of lameness was 5.5 ( $\pm 3 \mathrm{wk}$ ) (median 4 wk, interquartile range 2 to $7 \mathrm{wk}$ ). Only $48 \%$ of scores remained unchanged from one score to the next, but cows were unlikely to move more than 1 score in a 2 -wk period. Once cows were a certain MS for 2 observations they were more likely to remain at that MS than change score. Patterns of scores are given in Table 2.

Milk yield was highest in cows with MS 1 (Table 3). Cows produced $0.7 \mathrm{~kg} / \mathrm{d}$ and $1.6 \mathrm{~kg} / \mathrm{d}$ less milk when MS 2 or 3, respectively, compared with cows with MS 1 $(P<0.05)$. A reduction in yield was observed from $t-3$ before becoming MS $2(0.47 \mathrm{~kg} / \mathrm{d} ; 95 \% \mathrm{CI}: 0.12-0.82)$ or MS 3 (0.9 kg/d; $95 \% \mathrm{CI}: 0.16-1.6)$ and $t+2$ after recovering from MS $2(0.42 \mathrm{~kg} / \mathrm{d} ; 95 \% \mathrm{CI}: 0.09-0.75)$.

First-, second-, and third-lactation cows were 58, 48, and $19 \%$, respectively, less active (took fewer steps) than cows of parity $>3(P<0.05$; Table 3$)$. Cows were less active in early lactation (1.38 mean log steps/h in mo 1) and became more active as lactation progressed (1.74 mean log steps/h in mo 11); for example, cows that were 9 mo into lactation were $42 \%$ more active than those in the first month of lactation $(P<0.05)$. Cows with MS 0 were $1 \%$ less active than cows with MS $1(P<0.05)$. Cows with MS 2 and 3 were 3 and $5 \%$ less active, respectively, than cows with MS $1(P<0.05)$. 
Table 2. Transitions in mobility score (0 to 3 scale; see Table 1 ) from time $t-3$ to time $t$, where $t=14$-d intervals, illustrating that 50 to $60 \%$ of cows remain at a score for 8 wk but that 40 to $50 \%$ cows move mobility score

\begin{tabular}{lccccc}
\hline$t^{1}-3$ & $t-1$ & $t$ & $\begin{array}{c}\text { Probability } \\
\text { of score at } t\end{array}$ & $\begin{array}{c}\text { Sequence } \\
\text { observed, }{ }^{2} \mathrm{n}\end{array}$ \\
\hline 0 & $t-2$ & 0 & 0 & 0.57 & 244 \\
0 & 0 & 0 & 1 & 0.41 & 244 \\
1 & 0 & 0 & 1 & 0.51 & 182 \\
1 & 0 & 0 & 0 & 0.44 & 665 \\
1 & 0 & 1 & 1 & 0.65 & 665 \\
1 & 1 & 1 & 0 & 0.19 & 390 \\
2 & 1 & 2 & 3 & 0.64 & 54 \\
3 & 3 & 3 & 1 & 0.67 & 54 \\
3 & 3 & 3 & 2 & 0.02 & 54 \\
3 & 3 & 3 & 1 & 0.31 & 31 \\
3 & 3 & 3 & 1 & 0.67 & 54 \\
3 & 3 & 2 & 0.16 & 10 \\
2 & 3 & 2 & 1 & 0.20 & \\
1 & 3 & 2 & & & \\
\hline
\end{tabular}

${ }^{1} t=$ time, $t \pm \mathrm{i}=$ time from or to $t$ in 2 -wk intervals.

${ }^{2} \mathrm{n}=$ number of occasions.

Cows had decreased activity for 6 wk before being MS 2 (mean 0.02 steps/h; 95\% CI: 0.01-0.03): they were $2 \%$ less active $4 \mathrm{wk}$ before and $3 \%$ less active $2 \mathrm{wk}$ before they became MS 2 compared with cows with MS $1(P<0.05)$. Cows with MS 3 were less active from 4 wk before they developed MS 3 (0.02 steps/h; 95\% CI: 0.00-0.04). Similarly, cows that were MS 2 were less active by 3 to $4 \%$ for the following 5 recordings, and cows that were MS 3 were less active by 3 to $6 \%$ for the following recordings $(P<0.05)$.

In total, 444 lesions (185/100 cows per yr) with 385 primary lesions on 258 feet were recorded by the herdsman, veterinarian, and foot trimmer. Over the 12-mo study period, 178 cows $(57 \%)$ were treated for at least 1 lesion; 72 (23\%) cows had more than 1 foot with a lesion; and 81 (31\%) feet were treated more than once. The lesions recorded were digital dermatitis (39\%), sole ulcer $(25 \%)$, white line disease $(12 \%)$, interdigital growth $(9 \%)$, and other $(15 \%)$.

From the multistate model (Table 4), the longer a cow was not lame (i.e., not MS 2 or 3), the less likely she was to make a transition to being lame, and the longer a cow was lame, the less likely she was to recover from being lame. Cows $<90$ DIM were less likely to become lame than cows $\geq 90$ DIM [odds ratio $(\mathbf{O R})=$ $0.66]$ and cows with milk yield $>15$ to $\leq 35 \mathrm{~kg}$ in the previous $16 \mathrm{~d}$ were less likely to recover from lameness $(\mathrm{OR}=0.73)$ than cows with milk yield $>35 \mathrm{~kg}$.

Cows in parity $1(\mathrm{OR}=0.49)$ or $2(\mathrm{OR}=0.79)$ were less likely to become lame and they were more likely to recover $(\mathrm{OR}=1.26$ and 1.32 , respectively) once they had become lame compared with cows of parity $>2$. Lame cows with "other" lesions that were treated were less likely to recover from being lame $(\mathrm{OR}=0.58)$ than untreated lame cows. Cows treated for a sole ulcer (OR $=1.35)$, digital dermatitis $(\mathrm{OR}=1.51)$, or "other" lesion ( $\mathrm{OR}=1.39$ ) were more likely to become lame again compared with nonlame cows that had not been treated (Table 4).

\section{DISCUSSION}

In the current study, milk yield was reduced in cows with MS 2 or 3 for 6 to 8 wk before they became lame. This period was considerably less than the 3 to 4 mo when reduction in yield was observed before treatments reported by Green et al. (2002) and Amory et al. (2008) and suggests that a delay in treatment occurred in those 2 studies. If mobility scoring was used to identify lame cattle and they were treated promptly, the duration of lameness and milk loss might be reduced (Green et al., 2010). From the multistate model and patterns of MS (Tables 2 and 4), treatment in the current study herd was not successful, with treated cattle either not recovering (other lameness) or being more likely to become lame again (sole ulcer, digital dermatitis, and other diseases). Note that white line disease was not associated with lameness (Table 4) as in other studies (Tadich et al., 2010). Repeated occurrences of lameness might indicate a poor treatment strategy or efficacy, but might also indicate that treatment cannot address intrinsic factors causing lameness, such as a thin digital cushion. Treatment was added to the milk yield model; however, it did not alter the associations between yield and MS and so was excluded.

That nonlame cows had a lower milk yield for 4 to 8 wk before a change in mobility score to MS 2 or 3 suggests that the reduction in yield occurred before lame- 
Table 3. Random effects model of mean 16-d yield and 16-d mean log activity in 312 cows from 1 dairy herd in Somerset, UK

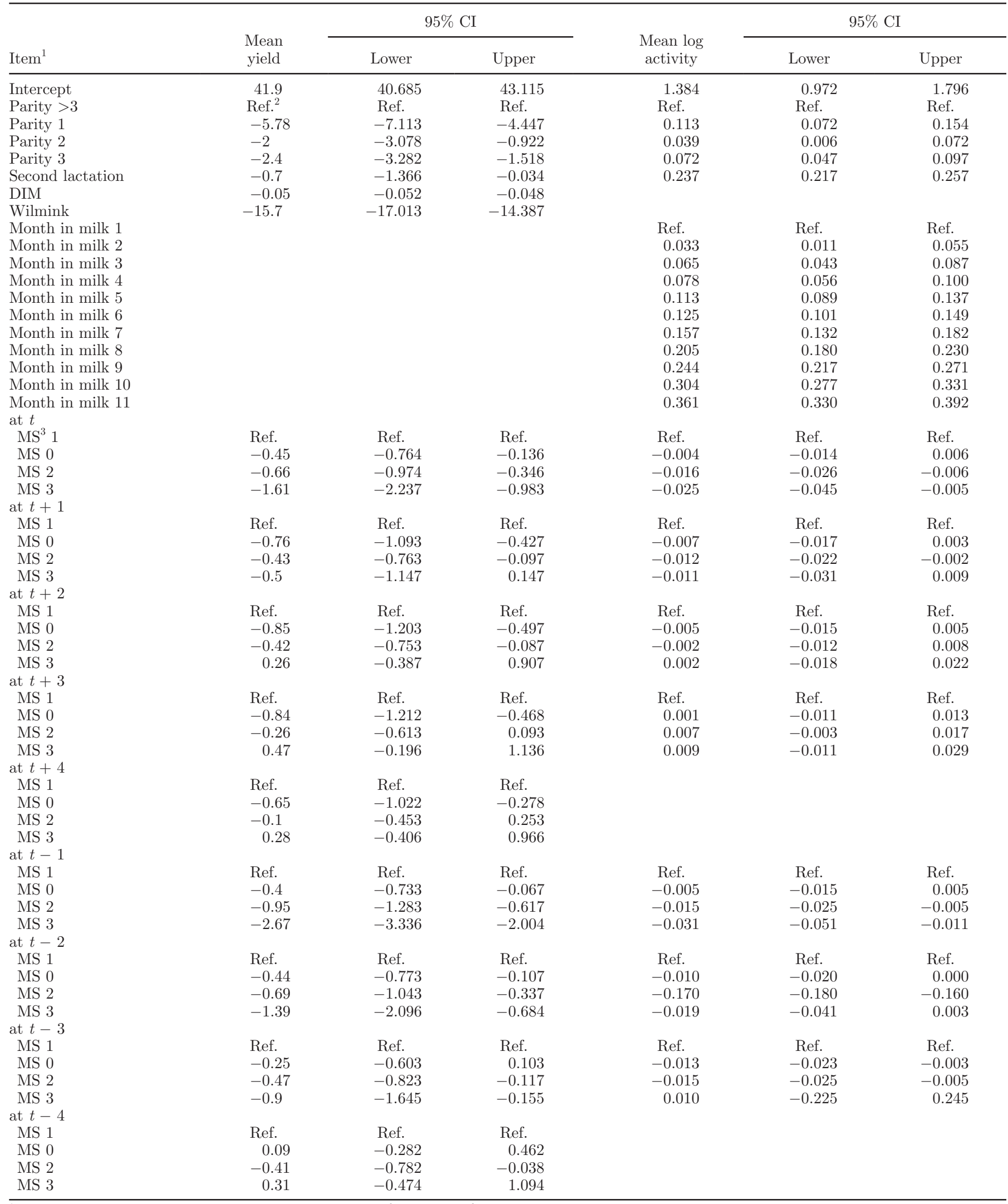

${ }^{1} t=$ time, $t \pm \mathrm{i}=$ time from or to $t$ in 2 -wk intervals. ${ }^{2}$ Reference. ${ }^{3} \mathrm{MS}=$ mobility score. 
Table 4. Multivariable multistate model of transitions between lame (mobility score 2 or 3 ) and nonlame (mobility score 0 or 1 ) states in 312 cows from 1 dairy herd observed for $1 \mathrm{yr}$ in Somerset, UK

\begin{tabular}{|c|c|c|c|c|}
\hline \multirow{2}{*}{$\frac{\text { Variable }}{\text { Intercept }}$} & \multicolumn{4}{|c|}{ Transition } \\
\hline & \multicolumn{2}{|c|}{ Nonlame to lame } & \multicolumn{2}{|c|}{ Lame to nonlame } \\
\hline & Odds ratio & $95 \%$ CI & Odds ratio & $95 \%$ CI \\
\hline \multicolumn{5}{|c|}{ Duration spent in state } \\
\hline$>4-18$ wk & 1.80 & $1.32-2.47$ & 1.93 & $1.01-3.69$ \\
\hline$>18 \mathrm{wk}$ & Ref. $^{1}$ & & Ref. & \\
\hline \multicolumn{5}{|l|}{ DIM } \\
\hline $0-90$ & 0.66 & $0.57-0.78$ & 1.25 & $0.93-1.67$ \\
\hline $91-180$ & 1.00 & $0.79-1.26$ & 1.15 & $0.91-1.46$ \\
\hline$>180$ & Ref. & & Ref. & \\
\hline \multicolumn{5}{|c|}{ Past treatments } \\
\hline \multicolumn{5}{|c|}{ Digital dermatitis } \\
\hline Yes & 1.51 & $1.29-1.76$ & 0.86 & $0.72-1.03$ \\
\hline No & Ref. & & Ref. & \\
\hline \multicolumn{5}{|c|}{ White line disease } \\
\hline Yes & 1.15 & $0.91-1.46$ & 0.83 & $0.65-1.05$ \\
\hline \multirow{2}{*}{\multicolumn{5}{|c|}{ Other }} \\
\hline & & & & \\
\hline Yes & 1.39 & $1.10-1.76$ & 0.58 & $0.45-0.74$ \\
\hline No & Ref. & & Ref. & \\
\hline \multicolumn{5}{|l|}{ Pregnant } \\
\hline Yes & 0.87 & $0.70-1.08$ & 1.67 & $1.34-2.07$ \\
\hline No & Ref. & & Ref. & \\
\hline \multicolumn{5}{|c|}{ Mean milk yield in previous $16 \mathrm{~d}$} \\
\hline \multicolumn{5}{|l|}{ Parity } \\
\hline 2 & 0.79 & $0.63-0.98$ & 1.32 & $1.05-1.67$ \\
\hline 3 & 0.94 & $0.74-1.19$ & 1.15 & $0.89-1.48$ \\
\hline$>3$ & Ref. & & Ref. & \\
\hline
\end{tabular}

${ }^{1}$ Reference.

ness was detectable. One explanation for the reduction in yield before MS changed is that mobility scoring is not sufficiently sensitive to detect the initial stages of disease. In other studies of dairy cow lameness, authors have reported lesions on sound cows (Manske et al., 2002; Bicalho et al., 2008; Tadich et al., 2010). Drawing evidence from Bicalho et al. (2009), lameness and foot lesions are positively associated with a thin digital cushion, which might cause subclinical disease that is not detectable externally or by mobility scoring, but is sufficiently painful to reduce food intake, increase metabolic rate, and thus reduce milk yield. An alternative hypothesis is that reduction in milk yield and lameness are on a common causal pathway, possibly linked to low body condition, which is correlated with a thin digital cushion (Bicalho et al., 2009). It is unfortunate that we did not score the body condition of cattle in the current study.

High-yielding cattle are at greater risk of lameness (Green et al., 2002, 2010; Amory et al., 2008). In the current study, cows with MS 1 produced more milk than cows with scores 0,2 , or 3 . These cows are producing high milk yields and their locomotion is impaired (they are marginally lame). Over time, a proportion remain 
at MS 1 (Tables 2 and 3 ) and continue to produce high yields (Table 3 ), but some move to MS 2 or 3 and the pattern of lower yield and higher mobility score ensues. Depending on farm layout, lame cows might feed less frequently and so reduce feed intake, exacerbating the disease process. If this were the case, then successful treatment might increase mobility and stabilize milk yield, as seen in Green et al. (2010).

A large number of transitions in MS were seen between 14-d-interval scores for individual cows in our study. In the UK, farmers often MS their cattle annually or biannually to comply with assurance scheme standards; the current results suggest that infrequent mobility scoring would give a snapshot of prevalence but have little value in management of lameness. Cows that had an MS of 2 or 3 had a high probability of remaining a 2 or 3 (Table 2 ) and becoming lame again (Tables 2 and 4 ). The effects of this may be seen in terms of milk production, but the effects on cow welfare are not so easy to quantify, although these cows did have lower activity. This suggests that prevalence, incidence, and repeat cases should be standard recordings.

The results demonstrate that it is not only the MS on the day of recording that is important; the length of time that a cow has been at a particular MS is also highly relevant. Our examples demonstrate that a cow that had been MS 2 for 6 wk lost $4.5 \mathrm{~kg} / \mathrm{d}$ of milk, whereas at MS 3 she lost $6 \mathrm{~kg} / \mathrm{d}$ of milk. These results support Juarez et al. (2003), who demonstrated a decrease in milk yield of $4 \mathrm{~kg} / \mathrm{d}$ for a lame cow. Extrapolating these results to a cow that is lame for 12 wk equates to 610 $\mathrm{kg}$ of milk lost, supporting Amory et al. (2008).

Results from this herd suggest that activity data may not play a useful role in early identification of lameness because the absolute changes were so small: parity and stage of lactation had a much greater effect on activity than did MS (Table 3 ). Cows became steadily more active as lactation progressed and with increasing parity, contrary to the findings of O'Callaghan et al. (2003), who reported a decreased level of activity as lactation progressed. The average change in activity associated with mobility score was less than $1 \% / \mathrm{d}$ in our study, whereas O'Callaghan et al. (2003) reported that cows that were lame were $24 \%$ less active than nonlame cows. Large variations might exist in activity between herds, which might depend on the farm layout, and could be an important factor when considering the necessary and unnecessary activity of cows.

The results suggest that a decrease in milk yield could have a role as an early indicator of lameness, whereas change in activity is a less sensitive measure. To be practically applied on farm, algorithms for milk yield, correcting for parity and stage of lactation, would need to be incorporated into on-farm software alongside daily milk recording. In conjunction with recording MS every $2 \mathrm{wk}$, this could alert the farmer to cows that need early intervention. Before this can be achieved, research needs to be repeated across many farms and systems to validate the findings. In addition, an unexpected reduction in milk yield might indicate that a cow is not metabolically stable (Bicalho et al., 2009) and lameness is only one of the risks for such cattle.

The advantage of this study was the large amount of detailed data that were collected. This farm was chosen because it was similar to many farms in the UK with Holsteins producing large quantities of milk under intensive conditions; the patterns within cow are useful additions to our understanding of the associations between milk yield, MS, activity, and lameness. A disadvantage of this study was that the data were from only one farm. It is not possible to generalize prevalence, incidence, and transitions between MS. Further work is required to elucidate when biochemical and pathological changes occur in the development of lameness. When these changes are identified, we can move forward in preventing lameness in dairy cows.

\section{CONCLUSIONS}

A reduction in mobility occurred 6 to 8 wk after milk yield had started to decline, and an increase in milk yield occurred approximately 4 wk after a cow returned to MS 0 or 1, suggesting that mobility scoring is insufficiently sensitive to detect lameness, that cattle mask lameness despite being diseased, or that lameness and reduction in yield are linked by a common intrinsic event. Once lame, cows were likely to remain lame or become lame again, suggesting that treatment was unsuccessful or that the internal origin of lameness overrode treatment. Further work investigating body condition, biochemical profiles, mobility, and lameness longitudinally could have a huge effect on our understanding of the etiology of lameness.

\section{ACKNOWLEDGMENTS}

We thank the RCVS Trust (London, UK) for supporting this research and the farmers for their assistance with data collection.

\section{REFERENCES}

Amory, J. R., Z. E. Barker, J. L. Wright, S. A. Mason, R. W. Blowey, and L. E. Green. 2008. Associations between sole ulcer, white line disease and digital dermatitis and the milk of 1824 dairy cows on 30 dairy cow farms in England and Wales. Prev. Vet. Med. 83:381-391.

Archer, S. C., M. J. Green, and J. N. Huxley. 2010. Association between milk yield and serial locomotion score assessments in UK dairy cows. J. Dairy Sci. 93:4045-4053. 
Barker, Z. E., J. R. Amory, J. L. Wright, S. A. Mason, R. W. Blowey, and L. E. Green. 2007. Management factors associated with impaired locomotion in dairy cows in England and Wales. J. Dairy Sci. 90:3270-3277.

Bicalho, R. C., V. S. Machado, and L. S. Caixeta. 2009. Lameness in dairy cattle: A debilitating disease or a disease of debilitated cattle? A cross-sectional study of lameness prevalence and thickness of the digital cushion. J. Dairy Sci. 92:3175-3184.

Bicalho, R. C., L. D. Warnick, and C. L. Guard. 2008. Strategies to analyze milk losses caused by diseases with potential incidence throughout the lactation: A lameness example. J. Dairy Sci. 91:2653-2661.

Clarkson, M. J., D. Y. Downham, W. B. Faull, J. W. Hughes, F. J. Manson, J. B. Merritt, R. D. Murray, W. B. Russell, J. E. Sutherst, and W. R. Ward. 1996. Incidence and prevalence of lameness in dairy cattle. Vet. Rec. 138:563-567.

Goldstein, H. 1995. Multilevel Statistical Models. Edward Arnold, London, UK.

Green, L. E., J. Borkert, G. Monti, and N. Tadich. 2010. Associations between lesion-specific lameness and the milk yield of 1635 dairy cows from seven herds in the Xth region of Chile and implications for the management of dairy cows worldwide. Anim. Welf. 19:419-427.

Green, L. E., V. J. Hedges, Y. H. Schukken, R. W. Blowey, and A. J. Packington. 2002. The impact of clinical lameness on the milk yield of dairy cows. J. Dairy Sci. 85:2250-2256.

Juarez, S. T., P. H. Robinson, E. J. DePeters, and E. O. Price. 2003 Impact of lameness on behavior and productivity of lactating Holstein cows. Appl. Anim. Behav. Sci. 83:1-14.

Leach, K. A., H. R. Whay, C. M. Maggs, Z. E. Barker, E. S. Paul, A. K. Bell, and D. C. J. Main. 2010. Working towards a reduction in cattle lameness: 1 . Understanding barriers to lameness control on dairy farms. Res. Vet. Sci. 89:311-317.
Manske, T., J. Hultgren, and C. Bergsten. 2002. Prevalence and interrelationships of hoof lesions and lameness in Swedish dairy cows. Prev. Vet. Med. 54:247-263.

Mazrier, H., S. Tal, E. Aizinbud, and U. Bargai. 2006. A field investigation of the use of the pedometer for the early detection of lameness in cattle. Can. Vet. J. 47:883-886.

O'Callaghan, K. A., P. J. Cripps, D. Y. Downham, and R. D. Murray. 2003. Subjective and objective assessment of pain and discomfort due to lameness in dairy cattle. Anim. Welf. 12:605-610.

Rasbash, J., Browne W. J., Healy M., Cameron B., and Charlton C. 2005. MLwiN Version 2.02. Centre for Multilevel Modelling, University of Bristol, UK.

Tadich, N., E. Flor, and L. E. Green. 2010. Associations between hoof lesions and locomotion score in 1098 unsound dairy cows. Vet. J. 184:60-65.

Walker, S. L., R. F. Smith, J. E. Routly, D. N. Jones, M. J. Morris, and H. Dobson. 2008. Lameness activity time budgets and estrus expression in dairy cattle. J. Dairy Sci. 91:4552-4559.

Warnick, L. D., D. Janssen, C. L. Guard, and Y. T. Grohn. 2001. The effect of lameness on milk production in dairy cows. J. Dairy Sci. 84:1988-1997.

Whay, H. R., D. C. Main, L. E. Green, and A. J. Webster. 2003. Assessment of the welfare of dairy cattle using animal-based measurements: Direct observations and investigation of farm records. Vet. Rec. 153:197-202.

Whay, H. R., A. E. Waterman, and A. J. Webster. 1997. Associations between locomotion, claw lesions and nociceptive threshold in dairy heifers during the peri-partum period. Vet. J. 154:155-161.

Wilmink, J. B. M. 1987. Adjustment of test-day milk, fat and protein yields. Livest. Prod. Sci. 16:335-348. 